\title{
GONZÁLEZ-FERNÁNDEZ, ADELA Y RODRÍGUEZ-TAPIA, SERGIO (EDS.) (2019). ESTUDIOS LINGÜIISTICOS EN TORNO AL TURISMO: TERMINOLOGÍA, CULTURA Y USUARIOS. VALENCIA: TIRANT HUMA- NIDADES. 290 PÁGINAS
}

\author{
CRistina Rodríguez Faneca \\ Universidad de Córdoba \\ cristina.rodriguez@uco.es \\ https://orcid.org/0000-0002-0940-666X
}

La publicación reseñada recopila diferentes trabajos que fueron presentados al I Congreso Internacional «Lenguas, Turismo y Traducción», celebrado en Córdoba en octubre de 2017. Centran su atención hacia una de las tres líneas temáticas que estructuran el volumen: la terminología, la cultura y los usuarios.

Ya en la introducción, los editores de la obra entablan una discusión acerca de la timidez con la que la Lingüística y sus disciplinas afines se han acercado a la Turismología. Es tanta esta timidez que apenas existen estudios que aborden la relación entre lenguas, turismo y traducción desde una perspectiva actual. Podemos nombrar algunas aportaciones, como las de Prieto-Arranz (2005), Fuentes-Luque (2005), Nobs (2006) y Almahano-Güeto y Postigo-Pinazo (2013). Paralelamente, los editores aportan datos del sector (OECD, 2018) que corroboran la importancia del turismo en la economía global y, por tanto, la pertinencia de las contribuciones que forman parte de la publicación.

La obra se inicia con una contribución de José María Castellano («El diario de viaje como guía turística: análisis de imágenes románticas en Le Tour d’Espagne en Automobile. Étude de Tourisme de Pierre Marge») que analiza el lenguaje literario de la obra de Marge. En este trabajo, la guía de viaje se erige como un documento transversal y de gran riqueza lingüística debido a que se plasman en ella impresiones, imágenes y pensamientos que evocan un determinado lugar. Al término del capítulo se extraen conclusiones tanto a nivel narrativo, turismológico y lingüístico como a nivel histórico y social; de estas conclusiones se desprende, en consecuencia, la utilidad de este tipo de texto como vía para indagar acerca de la realidad española en épocas pasadas.

El volumen continúa con un capítulo titulado «Terminología del turismo: turismo sostenible, responsable, ecoturismo...: cuando las palabras confunden a los viajeros», a cargo

Para citar esta reseña / To cite this book review: Rodríguez Faneca, Cristina (2020). Reseña de González-Fernández, Adela y Rodríguez-Tapia, Sergio (eds.) (2019). Estudios lingüísticos en torno al turismo: terminología, cultura y usuarios. Valencia: Tirant Humanidades. 290 Páginas. ELUA, 34: 237-240. https://doi.org/10.14198/ELUA2020.34.14

Enlace / Link: https://doi.org/10.14198/ELUA2020.34.14

(c) BY-NC Este trabajo se publica bajo una licencia de Creative Commons Reconocimiento-NoComercial 4.0 Internacional 
de María Lucía Carrillo Expósito. Este trabajo se inicia presentando sucintamente el desarrollo y estado de la cuestión del ecoturismo a la vez que se plantea una discusión sobre el galimatías terminológico que supone la dispersión terminológica existente en torno a esta modalidad turística. Posteriormente, tras el análisis del corpus propuesto, se describen y analizan las estrategias que usan las empresas turísticas para promocionar y hacer atractivos sus servicios en relación con el ecoturismo.

En su trabajo «La traducción de páginas web alemán-español en el sector turístico: el caso de la Deutsche Bahn», Ingrid Coboz López analiza y evalúa una parte de la página web del servicio ferroviario DB. Para ello, la autora se sirve, muy acertadamente, de los parámetros propuestos por Nobs (2003). Si bien este capítulo supone un acercamiento muy logrado a los problemas y soluciones que deben tenerse en cuenta a la hora de localizar un sitio web, la estructura y presentación del trabajo resulta demasiado sinuosa, en tanto que involucra muchas secciones distintas.

María del Carmen Balbuena Torezano nos acerca a la viticultura en su contribución titulada «La traducción de folletos informativos para el enoturismo: la D. O. Montilla-Moriles». La autora inicia el capítulo explicitando el concepto de enoturismo y continúa estudiando las características de los folletos informativos de este tipo de actividad, considerados una tipología textual híbrida. Antes de finalizar, aporta herramientas teóricas y metodológicas para la traducción de este tipo de textos, a caballo entre el texto vitivinicultural y el texto turístico. Se trata de una aportación clara y concisa, y que logra aproximar al lector a este tipo de texto de forma hábil.

En «El texto turístico: estudio y claves para su traducción», Isidoro Ramírez Almansa reflexiona acerca del texto turístico, sus características y sus funciones, para concluir con una máxima fundamental acerca de la importancia del análisis textual: éste determinará la función del texto y, por ende, su modo de abordaje y su traducción. Si bien este capítulo supone un meritorio acercamiento al análisis textual y a la hibridez de los textos turísticos, no llega a adentrarse del todo en la cuestión instrumental necesaria para su traducción (tal y como cabe esperar, teniendo en cuenta el título del propio trabajo).

El volumen continúa con un capítulo dedicado a las guías prácticas, y en concreto, guías con la combinación lingüística español $<>$ italiano. El estudio «Las estrategias de traducción de los términos gastronómicos italianos en las guías prácticas en español», a cargo de Francisco José Rodríguez Mesa, se centra en los términos gastronómicos para ilustrar uno de los fundamentos de su trabajo: en este tipo de documentos la unidad de trabajo no es lingüística, sino cultural. De esto se desprende que el traductor necesita dominar la cultura meta tanto como su propia cultura, siendo a la vez traductor y anfitrión. Destacamos la cuidadosa selección bibliográfica de esta aportación, tanto a la hora de instruirnos en el marco teórico como de llevar a cabo el análisis de las unidades propuestas, así como su precisión terminológica, claridad y concisión.

El capítulo firmado por Menghsuan $\mathrm{Ku}$ («Comparación de guías de idioma en chino y en español para viajeros: su enfoque, organización y la percepción cultural del otro») se centra en las guías de idiomas en chino y español. El corpus presentado está formado por tres guías totalmente distintas de las que se analizan aspectos, sobre todo, relacionados con la percepción cultural. La autora destaca la falta de revisión de este tipo de publicaciones, ya que se prima la rapidez de publicación sobre otros aspectos. 
El trabajo «Sobre los conocimientos de la cultura meta necesarios para la traducción de textos turísticos en lenguas eslavas (ruso y checo)» (Ekaterina Guerbek y Lenka Zamisova) se centra en aspectos culturales de la traducción de textos turísticos y en los conocimientos que ha de poseer el traductor para solventar los obstáculos del texto original. Una vez más, se subraya la importancia de los aspectos culturales y se hace hincapié en los efectos de la percepción intercultural en la traducción.

Marta Guirao Ochoa presenta un texto titulado «Función comunicativa y estrategias traductológicas: comparativa de dos entornos museísticos virtuales». En él se analizan las páginas webs de la sede virtual del Museo del Prado y la exposición virtual de la Biblioteca Nacional de España. Se centra en sus características, estrategias de traducción y adaptación $\mathrm{y}$, sobre todo, en cómo influyen las decisiones del traductor en la experiencia virtual del visitante. Destacamos lo novedoso de esa aportación, que contribuye a una línea de investigación incipiente en los Estudios de Traducción.

En «El fenómeno de la adaptación lingüística y cultural en la traducción de textos turísticos: comparación de dos lenguas tipológicamente afines», Giuseppe Trovato reflexiona de nuevo sobre las dificultades lingüísticas culturales de los textos turísticos, aunque en este caso se trabaja con un obstáculo añadido: la afinidad entre lenguas (en este caso, italiano<>español). El trabajo se centra en tres aspectos propios de los textos turísticos: siglas y acrónimos, gastronomía y topónimos. Posteriormente, se reseñan las herramientas más apropiadas para realizar el trasvase lingüístico y cultural. Cabe destacar que resultan muy acertadas las referencias bibliográficas usadas al tratar las lenguas afines, así como la propia estructura del trabajo y el gran cuidado en su redacción.

El capítulo «Guías de viajeros, hoteles y publicidad en el siglo XIX», a cargo de Manuela Álvarez Jurado, está dedicado a las guías de viajes publicadas y distribuidas por hoteles parisinos. Nos muestra cómo, a través del estudio de las características principales, estructura y contenido de las guías, es posible obtener información de índole sociocultural e histórica con gran exactitud.

En «El uso del superlativo en textos promocionales sobre Extremadura: análisis de corpus», Manuel Sánchez García analiza las características de un conjunto de textos del Travelling around Extremadura Corpus (entre ellos, folletos, mapas y guías de viaje) para obtener información acerca del uso de las estructuras superlativas y así determinar si este es más intenso que en otros géneros textuales. Merece la pena resaltar la pulcritud de la redacción del trabajo, así como la pertinencia de las aclaraciones que hace el autor durante su transcurso, como la acotación del concepto de epíteto y su posterior agrupación.

Adrián Fuentes Luque se adentra en la complejidad del texto turístico a través del estudio del caso de España en «La traducción en la promoción turística: el caso de España, marca e imagen». Tras instruir al lector acerca de las características del texto turístico y las particularidades de España como destino vacacional, se analizan y reseñan las distintas campañas y eslóganes con los que España se ha posicionado en el exterior a lo largo de los años; al término, se reflexiona sobre la creación y el mantenimiento de la imagen de marca, así como sobre su importancia en el contexto de la promoción turística.

El estudio "La aceptabilidad de traducciones turísticas: un estudio centrado en el usuario» de Jorge Soto Almela supone un estudio empírico con grandes implicaciones para los entes encargados de promocionar los destinos turísticos. En concreto, su trabajo se centra en el diseño de una investigación que, a través del uso de técnicas comparativas, permita 
comparar las distintas estrategias de traducción que inciden, en última instancia, en la aceptabilidad que los turistas puedan otorgar a la traducción de culturemas foráneos. Debemos subrayar la calidad metodológica de este trabajo y el éxito obtenido a la hora de poner en práctica nociones teóricas relacionadas con culturemas, técnicas de traducción y aceptabilidad por parte del usuario.

En «Estudio panorámico de la relación entre la interpretación de lenguas y el turismo: el caso de Andalucía», Aurora Ruiz Mezcua expone, al inicio, el estado de la cuestión en cuanto a la implantación del grado conjunto de Traducción e Interpretación y Turismo. En la segunda parte del trabajo se enumeran las principales técnicas y modalidades de interpretación empleadas en el sector del turismo. Se trata de un trabajo que estructura hábilmente la ingente cantidad de información que proporciona, y que pone en valor, además, el papel del intérprete en el contexto turístico.

El volumen cierra con una contribución firmada por María del Carmen Moreno Paz. En «La traducción y localización de páginas web institucionales de promoción turística: propuesta metodológica de análisis contrastivo a partir de un estudio de caso (español-inglés)», la autora analiza mediante un enfoque cuantitativo la web del Ayuntamiento de Córdoba; en concreto, una sección dedicada a la promoción turísticas del Alcázar de los Reyes Cristianos. Destaca por la precisión de su metodología (a la par que en la propia exposición de la misma, extendiendo así su acertada propuesta), por la clara explicación de los resultados y por la valoración crítica de las traducciones.

Antes de finalizar nos gustaría destacar uno de los puntos fuertes de la obra: el protagonismo que se ha otorgado, de manera compartida, a varias lenguas: el alemán, el checo, el chino, el francés, el inglés, el italiano y el ruso. Además de esto, nos gustaría referir sucintamente un aspecto esencial de la maquetación en relación con el índice de la obra, ya que no aparece el nombre de los autores de cada contribución; por ello, no es posible saber a quién corresponde cada una de ellas hasta que no se busca en el interior del libro. Para concluir, resaltamos lo novedoso de este monográfico y la rigurosidad con la que la mayoría de trabajos abordan la relación entre el turismo, la traducción y las lenguas, si bien esperamos que en futuras contribuciones podamos contar con más estudios empíricos fruto de las reflexiones aquí recopiladas.

\section{REFERENCIAS BIBLIOGRÁFICAS}

Almahano-Güeto, I. y Postigo-Pinazo, E. (eds.). (2013). Turismo y salud: traducción, interpretación y comunicación intercultural en el sector turístico europeo. Granada: Comares.

Fuentes-Luque, A. (2005). La traducción en el sector turístico. Granada: Atrio.

Nobs, M. L. (2003). Expectativas y evaluación en la traducción de folletos turísticos: estudio empírico con usuarios reales. Tesis doctoral. Granada: Universidad de Granada.

Nobs, M. L. (2006). La traducción de folletos turísticos: ¿qué calidad demandan los turistas? Granada: Comares.

OECD (2018). OECD Tourism Trends and Policies 2018. Paris: OECD Publishing.

Prieto-Arranz, J. I. (2005). A (dis)United Kingdom: the discourse of British tourist promotion and its translation into Spanish. Oviedo: Universidad de Oviedo, Servicio de Publicaciones. 